\title{
Analysis of blood pressure control in outpatients with non-dialysis chronic kidney disease referred by primary care physicians: a study from the centre of nephrology care
}

\author{
Olexandr Kuryata', Tetiana Yashenko ${ }^{2}$, Viktor Semenov ${ }^{1}$ \\ 'Department of Internal Medicine 2, Dnipropetrovsk Medical Academy of Health Ministry of Ukraine, Dnipropetrovsk, Ukraine \\ ${ }^{2}$ Department of Nephrology, Dnipropetrovsk Mechnikov Regional Hospital, Dnipropetrovsk, Ukraine
}

\begin{abstract}
Background. Patients with chronic kidney disease (CKD) have increased all-cause mortality, especially cardiovascular. The majority of patients with CKD have stages 1-3 and are treated by primary care physicians and nephrologists. Arterial hypertension (HTN) is highly prevalent comorbidity among CKD population, but its control remains poor. Material and methods. This retrospective non-interventional cross-sectional study was conducted in the Centre of Nephrology Care in Dnipropetrovsk Mechnikov Regional Hospital, Dnipro, Ukraine. We aimed to select patients who are supposed to be followed-up by primary care practitioners but due to certain reasons required nephrologist's consultation. From 4540 patients who received medical care in the Centre of Nephrology Care 365 patients fulfilled inclusion criteria. They were subdivided by presence of HTN, CKD stage, presence of proteinuria and achieving blood pressure targets according to different standards. All patients were examined and followed-up according to local and European standards.

Results. Forty-nine percent of patients had known HTN, and 21\% had HTN de novo. Advance of CKD stage was significantly associated with increase in the most of laboratory findings, age and BP values. Non-proteinuric patients achieved BP goals significantly more often, than proteinuric ones. Females achieved BP targets more often, than males. Monotherapy was the most common treatment regimen.

Conclusions. HTN occurs in $70 \%$ of patients with CKD and it is controlled in up to $34 \%$ of cases. HTN is important factor of CKD progression and it is closely connected with GFR and proteinuria.

Key words: arterial hypertension; chronic kidney disease; primary care
\end{abstract}

Arterial Hypertens. 2019, vol. 23, no. 2, pages: 88-97

DOI: $10.5603 / A H . a 2019.0004$

Address for correspondence: Viktor Semenov, MD

Department of Internal Medicine 2, Dnipropetrovsk Medical Academy of Health Ministry of Ukraine, Vernadsky Street, 9, 49044 Dnipro, Ukraine, e-mail: kinsolwing@gmail.com

V M Copyright $\odot 2019$ Via Medica, ISSN 2449-6170 


\section{Introduction}

Patients with chronic kidney disease (CKD) have increased risk of mortality, cardiovascular (CV) disease and development of end-stage renal disease (ESRD) [1]. The majority of patients with CKD have stages 1-3 and are treated by primary care physicians (PCPs) and nephrologists [2]. Management of patients with early-stages $\mathrm{CKD}$ is problematic, because there is no sufficient evidence on the expediency of early CKD intervention [2].

Arterial hypertension (HTN) is highly prevalent in CKD population [3] and it is the second cause of end-stage renal disease worldwide [4]. Control of HTN in CKD patients remains suboptimal regardless of region and it may be due to various reasons: poorly controlled HTN in advanced stages of CKD, low awareness of HTN treatment guidelines in CKD patients, inadequate drug or dose choice etc. [2]. Importantly, CKD patients are older than in general population [5] and may require different blood pressure (BP) targets [6]. In elderly individuals, age-related decline in glomerular filtration rate (GFR) may be difficult to differentiate from CKD [7].

But for the majority of patients with CKD it is still uncertain what BP targets should be chosen and what should be taken into consideration before choosing BP target. BP management guidelines, provided by International Society of Nephrology (KDIGO) [8], European Society of Cardiology (ESC) [9] and American College of Cardiology (ACC) [10] and issued between $2012^{\text {th }}$ and $2017^{\text {th }}$ tended to get stricter with time and 2017 ACC guidelines recommend target $\mathrm{BP}$ for patients with CKD to be $<130 / 80 \mathrm{~mm} \mathrm{Hg}$. But despite convincing results of SPRINT trial [11], showing benefits of strict BP control in patients with CKD, Hypertension Canada's 2018 Guidelines for Diagnosis, Risk Assessment, Prevention, and Treatment of Hypertension in Adults and Children [12] changed BP goals for patients with CKD to $<140 / 90 \mathrm{~mm} \mathrm{Hg}$, leaving BP target $<130 / 80 \mathrm{~mm} \mathrm{Hg}$ for patients with diabetes mellitus (DM).

Results of SPRINT trial may be difficult to extrapolate to general CKD population due to exclusion from the trial patients with DM and heart failure and due to the method of BP measurement, showing BP values from 5 to $20 \mathrm{mmHg}$ lower, than could be obtained using routine methods [5]. At the same time data about inverse relationship of BP and patients' negative clinical outcomes are accumulating. Concept of so-called $J$ curve was emerged and confirmed by several researchers and inverse association with BP was fair only for allcause mortality, but not for incidence of coronary heart disease, ischaemic stroke or ESRD [5]. Notably, adverse impact of low BP values on the risk of CV death was more prominent, than the impact of high BP [5].

The aim of this study is to assess BP control in patients with non-dialysis CKD referred by PCPs to the Centre of Nephrology Care.

\section{Material and methods}

This retrospective non-interventional cross-sectional study was conducted in the Centre of Nephrology Care in Dnipropetrovsk Mechnikov Regional Hospital, Dnipro, Ukraine. We aimed to select patients who are supposed to be followed-up by primary care practitioner (PCP), but which due to certain reasons required nephrologist's consultation. Overall 4540 patients received medical care in Centre of Nephrology Care in Dnipropetrovsk Mechnikov Regional Hospital during 2017. We excluded patients with type $1 \mathrm{DM}$, polycystic renal disease, hereditary renal diseases, operations on kidneys or urinary tract ( $\mathrm{n}=874$ ) because they require multidisciplinary medical approach and are not treated by PCPs. We also excluded patients with GFR $<30 \mathrm{ml} / \mathrm{min}$ $(\mathrm{n}=351)$ as also requiring cooperation of nephrologist with other specialists due to CKD complications and preparing patients to renal replacement therapy. On the next step independent expert excluded 2950 patients as those that had no CKD or didn't require re-examination and could be followed-up in primary care. Thus, into the study were enrolled 365 patients with CKD that were followed-up in primary care, but required re-examination (including assessment of proteinuria, GFR and BP control) or revision of the treatment. All patients were examined and followed-up according to local and European standards and gave informed written consent on data collection. The study was approved by the Ethics Committee at the Dnipropetrovsk Mechnikov Regional Hospital, Dnipro, Ukraine. Study design is shown on Figure 1.

BP control was assessed according to following standards: KDIGO Clinical Practice Guideline for the Management of Blood Pressure in Chronic Kidney Disease [8] (BP goal $\leq 140 / 90 \mathrm{~mm} \mathrm{Hg}$ or $\leq 130 / 80 \mathrm{~mm} \mathrm{Hg}<$ if albumin excretion rate (AER) > $30 \mathrm{mg} / 24$ hours); 2013 ESH/ECS Guideline for management of HTN [9] (BP goal - systolic BP $(\mathrm{SBP})<140 \mathrm{~mm} \mathrm{Hg}) ; 2016$ European guidelines on $\mathrm{CV}$ disease prevention in clinical prac- 


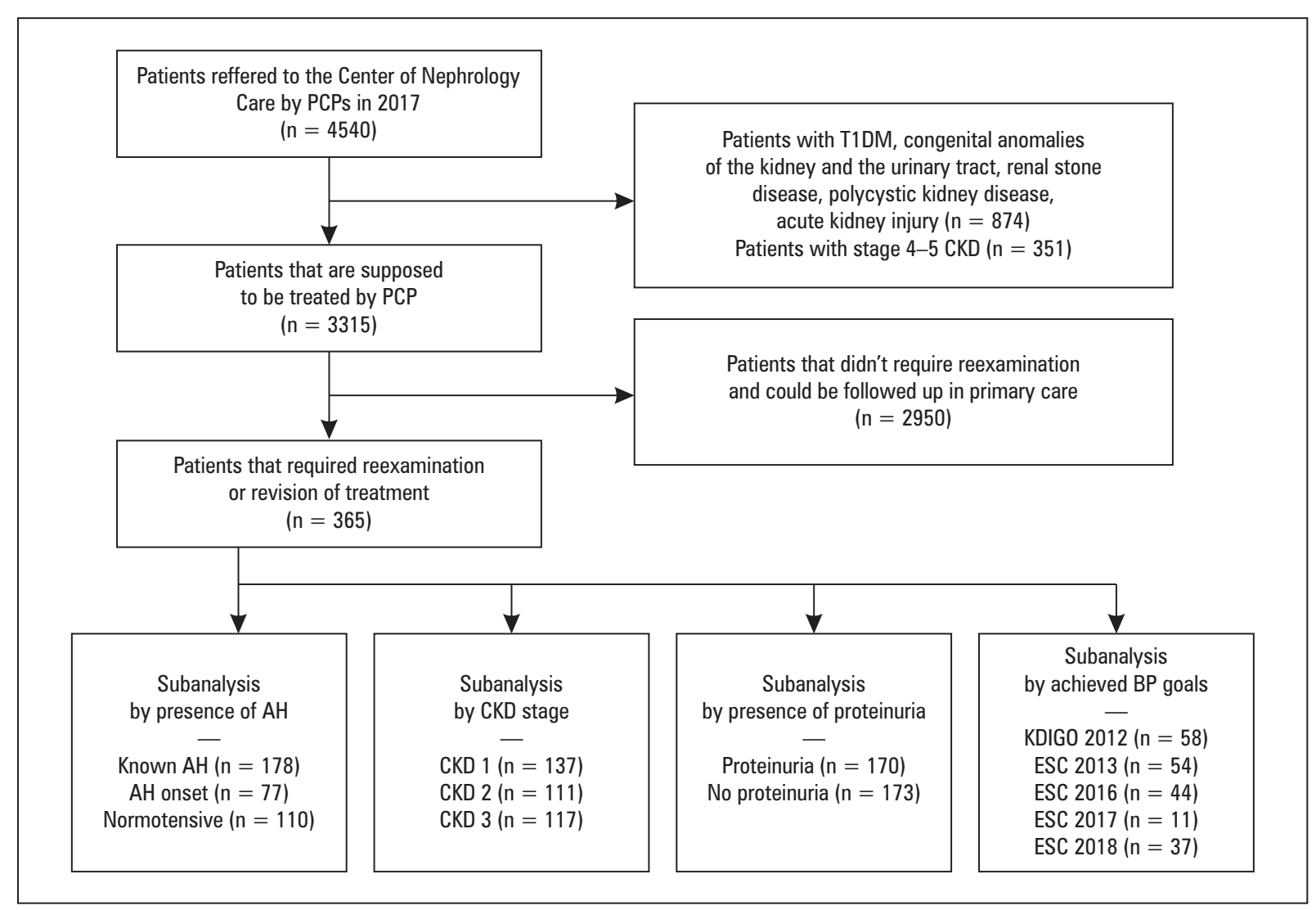

Figure 1. Study design. PCPs — primary care physicians; T1DM — type 1 diabetes mellitus; CKD — chronic kidney disease; HTN — arterial hypertension; KDIGO — Kidney Disease Improving Global Outcomes; ESC — European Society of Cardiology; ACC — American College of Cardiology; CCS - Canadian Cardiovascular Society

tice [13] (BP goal < 140/90 mm Hg); $2017 \mathrm{ACC} /$ AHA/AAPA/ABC/ACPM/AGS/APhA/ASH/ASPC/ NMA/PCNA Guideline for the Prevention, Detection, Evaluation, and Management of High Blood Pressure in Adults [10] (BP goal $<130 / 80 \mathrm{~mm} \mathrm{Hg}$ ) and Hypertension Canada's 2018 Guidelines for Diagnosis, Risk Assessment, Prevention, and Treatment of Hypertension in Adults and Children [12] (BP goal $<140 / 90 \mathrm{~mm} \mathrm{Hg}$ or $<130 / 80 \mathrm{~mm} \mathrm{Hg}$ for patients with DM). HTN was diagnosed in case of previously existing diagnosis of HTN or SBP $\geq 140 \mathrm{~mm} \mathrm{Hg}$ or DBP $\geq 90 \mathrm{~mm} \mathrm{Hg}$ at the moment of admission to the Centre of Nephrology Care. At the moment of data collection patients with known HTN were already prescribed antihypertensive treatment. In order to examine the effectiveness of treatment regimens (count and classes of drugs) we compared these patients to those, who achieved BP goals according to different standards.

Anaemia was diagnosed if haemoglobin was $<120 \mathrm{~g} / \mathrm{L}$ in females and $<130 \mathrm{~g} / \mathrm{L}$ in males. Left ventricular hypertrophy (LVH) was diagnosed using Sokolow-Lyon index after 12-lead electrocardiography. Proteinuria was diagnosed if urine albumin excretion was $>0.03 \mathrm{~g} / \mathrm{L}$ or protein trace was found in morning urine void. Risk of CKD progression was assessed according to KDIGO 2012 Clinical Practice Guideline for the Evaluation and Management of Chronic Kidney Disease [14]. In purpose to classify patients to albuminuria categories we used albumin excretion rate (AER). Body mass index (BMI) was estimated as weight $(\mathrm{kg}) /[\text { height }(\mathrm{m})]^{2}$. GFR was calculated using GFR-EPI equation [14].

\section{Statistical analysis}

Due to skewness of the data distribution, values were presented as median and interquartile range (IQR). Categorical data are presented as n (valid \%) to avoid confounding true proportion by missing data. Mann-Whitney and Kruskal-Wallis test were used to compare continuous data, $\chi^{2}$ test was used for comparing categorical data. Non-parametric Spearman's correlation coefficient $(\rho)$ was used. In most cases critical value of $\mathrm{p}$ was $<0.05$. In cases of multiple comparisons we used Bonferroni correction and critical value of p equalled to $0.05 /$ (number of possible comparisons). Data analysis was performed using Libre Office and R. 


\section{Results}

Majority of patients were females, but in group of patients with HTN de novo males predominated. Nearly $70 \%$ of patients had known HTN or HTN de novo. Median age differed significantly with distance of more than 10 years, being the highest in patients with known HTN. BMI, as well as age, was higher in hypertensive patients, especially in those with known HTN. DM, LVH and proteinuria were revealed more often in hypertensive patients, while anaemia (non-significantly) - in normotensive ones. Patients with HTN also had higher cholesterol levels and lower GFR, but there was no significant difference in CKD duration between groups. Normotensive patients had normal median GFR, while in hypertensive patients renal function was mildly or moderately decreased. Hypertensive patients contributed mainly to high risk groups of CKD progression.

Clinical characteristics of patients in the study are shown in the Table I. Clinical characteristics of patients with preserved renal function depending on presence of proteinuria are presented in the Table II. Information about treatment regimens of patients, who achieved BP control according to different standards and patients' characteristics are shown in Table III.

Prevalence of comorbid conditions increased as GFR declined (Fig. 2). Distribution of patients with low, moderately high, high and very high risk of CKD progression was the following: patients with stage 1 CKD - 66\%, 23\%, 1\%, 0\%; patients with stage 2 CKD - 69\%, 19\%, 12\%, 0\%; patients with stage 3 CKD - 0\%, 29.8\%, 35.1\%, 35.1\%. Decline in GFR was significantly associated with rise of median age $(\rho=-0.56)$, SBP $(\rho=-0.38)$, $\operatorname{DBP}(\rho=-0.28)$, BMI $(\rho=-0.41)$, serum uric acid $(\rho=-0.44)$, HTN duration $(\rho=-0.36 ; \mathrm{p}<0.001$ for all correlations) and with $\operatorname{AER}(\rho=-0.14 ; \mathrm{p}=0.019)$.

Patients with proteinuria had higher prevalence of DM and HTN and more often suffered from anaemia and LVH (Tab. II). In both groups patients had

Table I. Clinical characteristics of patients in the study

\begin{tabular}{|c|c|c|c|c|c|}
\hline \multirow{2}{*}{\multicolumn{2}{|c|}{ Parameter }} & Total & Known HTN & HTN de novo & Normotensive \\
\hline & & \multicolumn{4}{|c|}{ N (valid \%) } \\
\hline \multicolumn{2}{|l|}{ Total } & $365(100.0)$ & $178(48.8)$ & $77(21.0)$ & $110(30.1)$ \\
\hline \multicolumn{2}{|l|}{ Male $e^{a, c}$} & $155(42.5)$ & $68(38.2)$ & $44(57.1)$ & $43(39.1)$ \\
\hline \multicolumn{2}{|l|}{ Female $^{\mathrm{a}, \mathrm{c}}$} & $210(57.5)$ & $110(61.8)$ & $33(42.9)$ & $67(60.9)$ \\
\hline \multicolumn{2}{|l|}{$\mathrm{DM}^{\mathrm{b}}$} & $61(16.7)$ & $48(27.0)$ & $12(15.6)$ & $1(0.9)$ \\
\hline \multicolumn{2}{|l|}{ Anaemia } & $103(28.2)$ & $50(28.1)$ & $14(18.1)$ & $39(35.5)$ \\
\hline \multicolumn{2}{|l|}{$\mathrm{LVH}^{\mathrm{b}, \mathrm{c}}$} & $77(21.1)$ & $62(34.8)$ & $14(18.2)$ & $1(0.9)$ \\
\hline \multicolumn{2}{|c|}{ Proteinuria $a^{b, c}$} & $170(49.6)$ & $90(52.9)$ & $42(58.3)$ & $38(37.6)$ \\
\hline \multirow{4}{*}{$\begin{array}{l}\text { Risk of } \\
\text { CKD pro- } \\
\text { gression }\end{array}$} & Low & $125(45.0)$ & $51(34.9)$ & $27(46.6)$ & $47(63.5)$ \\
\hline & Moderately high & $66(23.7)$ & $39(26.7)$ & $11(19.0)$ & $16(21.6)$ \\
\hline & High & $54(19.4)$ & $31(21.2)$ & $14(24.1)$ & $9(12.2)$ \\
\hline & Very high & $33(11.9)$ & $25(17.1)$ & $6(10.3)$ & $2(2.7)$ \\
\hline & \multicolumn{4}{|c|}{ Median [IOR] } \\
\hline \multicolumn{2}{|c|}{ Age (years) ${ }^{a, b, c}$} & $44[29.5 ; 60]$ & $57[44.7 ; 66]$ & $40[31 ; 53]$ & $29.5[24 ; 38.2]$ \\
\hline \multicolumn{2}{|c|}{ BMI $\left[\mathrm{kg} / \mathrm{m}^{2}\right]^{\mathrm{a}, \mathrm{b}, \mathrm{c}}$} & $26.1[22.2 ; 30.8]$ & $29.3[25.6 ; 32.1]$ & $26[22.7 ; 30.8]$ & $21.6[19.6 ; 24.6]$ \\
\hline \multicolumn{2}{|c|}{ CKD duration (years) } & $5[1 ; 15.7]$ & $6[2 ; 15.5]$ & $8[2 ; 19.5]$ & $4[1 ; 12]$ \\
\hline \multicolumn{2}{|c|}{ HTN duration (years) ${ }^{a, b, c}$} & $0[0 ; 8]$ & $5.5[0 ; 13]$ & $0[0 ; 0]$ & $0[0 ; 0]$ \\
\hline \multicolumn{2}{|c|}{$\mathrm{SBP}[\mathrm{mm} \mathrm{Hg}]^{a, b, c}$} & $130[120 ; 150]$ & $140[130 ; 160]$ & $135[122.5 ; 150]$ & $110[100 ; 120]$ \\
\hline \multicolumn{2}{|c|}{$\mathrm{DBP}[\mathrm{mm} \mathrm{Hg}]^{\mathrm{b}, \mathrm{c}}$} & $85[75 ; 95]$ & $90[80 ; 100]$ & $90[80 ; 95]$ & $70[70 ; 80]$ \\
\hline \multicolumn{2}{|c|}{ GFR [mL/min] $]^{a, b, c}$} & $79.3[51.5 ; 101.6]$ & $60.5[44.5 ; 86.6]$ & $80.7[58.0 ; 99.2]$ & $102.2[80.5 ; 117.9]$ \\
\hline \multicolumn{2}{|c|}{ Uric acid $[\mu \mathrm{mol} / \mathrm{L}]$} & 391 [318;483] & 395 [314;483] & $369.5[321 ; 466]$ & $411[316 ; 507]$ \\
\hline \multicolumn{2}{|c|}{ Total cholesterol [mmol/L] } & $5.2[4.4 ; 5.9]$ & $5.2[4.5 ; 5.8]$ & $5.7[4.5 ; 6.6]$ & $4.9[3.8 ; 6.4]$ \\
\hline \multicolumn{2}{|c|}{ AER [mg/24 h] } & $0[0 ; 72]$ & $0[0 ; 72]$ & $0[0 ; 117]$ & $0[0 ; 51]$ \\
\hline
\end{tabular}

HTN — arterial hypertension; CKD — chronic kidney disease; DM — diabetes mellitus; LVH — left ventricle hypertrophy; BMI — body mass index; SBP — systolic blood pressure; DBP — diastolic blood pressure; GFR - glomerular filtration rate; AER — albumin excretion rate; " "Known HTN" vs. "HTN de novo"; "Known HTN" vs. "Normotensive"; " c"HTN de novo" and "Normotensive", p < 0.016 for all comparisons 
Table II. Clinical characteristics of patients depending on presence of proteinuria

\begin{tabular}{|c|c|c|c|c|}
\hline \multirow{2}{*}{\multicolumn{2}{|c|}{ Parameter }} & With proteinuria & Without proteinuria & \multirow[t]{2}{*}{$P$ value } \\
\hline & & \multicolumn{2}{|c|}{ N (valid \%) } & \\
\hline \multicolumn{2}{|l|}{ Total } & $170(49.5)$ & $173(50.5)$ & \\
\hline \multicolumn{2}{|l|}{ Males } & $71(41.8)$ & $77(45.5)$ & 0.60 \\
\hline \multicolumn{2}{|l|}{ Females } & $99(58.2)$ & $96(55.5)$ & 0.60 \\
\hline \multicolumn{2}{|l|}{ DM } & $33(19.4)$ & $26(15.0)$ & 0.28 \\
\hline \multicolumn{2}{|l|}{ Anaemia } & $63(37.1)$ & $33(19.1)$ & $<0.001$ \\
\hline \multicolumn{2}{|l|}{ LVH } & $43(25.3)$ & $33(19.9)$ & 0.06 \\
\hline \multicolumn{2}{|l|}{ HTN } & $132(77.6)$ & $110(63.6)$ & 0.004 \\
\hline \multirow{5}{*}{$\begin{array}{l}\text { Controlled HTN according } \\
\text { to guidelines }\end{array}$} & KDIGO 2012 & $56(32.9)$ & $26(72.8)$ & $<0.001$ \\
\hline & ESC 2013 & $78(45.9)$ & $112(64.7)$ & 0.02 \\
\hline & ESC 2016 & $63(37.1)$ & $99(52.7)$ & 0.014 \\
\hline & ACC 2017 & $30(17.6)$ & $52(30.1)$ & 0.15 \\
\hline & CCS 2018 & $59(34.7)$ & $92(53.2)$ & 0.045 \\
\hline \multirow{4}{*}{ ESC grades of BP } & Normal & $25(18.9)$ & $36(32.7)$ & \\
\hline & Grade 1 HTN & $53(40.2)$ & $49(44.5)$ & \\
\hline & Grade 2 HTN & $36(27.3)$ & $18(16.4)$ & \\
\hline & Grade 3 HTN & $18(13.6)$ & $7(6.4)$ & \\
\hline \multirow{5}{*}{ Class of drug } & ACEI & $26(15.3)$ & $32(18.5)$ & 0.42 \\
\hline & ARB & $36(21.2)$ & $28(16.2)$ & 0.23 \\
\hline & Diuretics & $23(13.5)$ & $15(8.7)$ & 0.15 \\
\hline & Beta-blockers & $41(24.1)$ & $24(13.9)$ & 0.015 \\
\hline & CCB & $24(14.1)$ & $9(5.2)$ & 0.005 \\
\hline & & \multicolumn{2}{|c|}{ Median [IQR] } & \\
\hline \multicolumn{2}{|l|}{ Age (years) } & $45[31 ; 59]$ & $45[28.5 ; 61]$ & 0.89 \\
\hline \multicolumn{2}{|l|}{ BMI $\left[\mathrm{kg} / \mathrm{m}^{2]}\right.$} & $26.4[22.6 ; 30.8]$ & $26.0[22.0 ; 30.8]$ & 0.58 \\
\hline \multicolumn{2}{|l|}{ CKD duration (years) } & $5[2 ; 13.2]$ & $6[1 ; 16.7]$ & 0.58 \\
\hline \multicolumn{2}{|l|}{ HTN duration (years) } & $0[0 ; 6.5]$ & $0[0 ; 9]$ & 0.89 \\
\hline \multicolumn{2}{|l|}{ SBP [mm Hg] } & $140[120 ; 150]$ & $130[110 ; 140]$ & $<0.001$ \\
\hline \multicolumn{2}{|l|}{$\mathrm{DBP}[\mathrm{mm} \mathrm{Hg}]$} & $90[80 ; 100]$ & $80[75 ; 90]$ & 0.001 \\
\hline \multicolumn{2}{|l|}{ GFR $[\mathrm{mL} / \mathrm{min}]$} & $68.1[45.6 ; 99.4]$ & $85.4[62.2 ; 106.4]$ & $<0.001$ \\
\hline \multicolumn{2}{|l|}{ Uric acid $[\mu \mathrm{mol} / \mathrm{L}]$} & $414[328 ; 502]$ & $360[302 ; 440]$ & 0.056 \\
\hline \multicolumn{2}{|l|}{ Total cholesterol [mmol/L] } & $5.5[4.8 ; 6.2]$ & $5.1[4.2 ; 5.7]$ & 0.13 \\
\hline
\end{tabular}

DM — diabetes mellitus; LVH — left ventricle hypertrophy; HTN — arterial hypertension; KDIGO — Kidney Disease Improving Global Outcomes; ESC — European Society of Cardiology; ACC — American College of Cardiology; CCS - Canadian Cardiovascular Society; ACEI — angiotensin converting enzyme inhibitors; ARB — angiotensin receptor blockers; CCB — calcium channel blockers; BMI — body mass index; CKD — chronic kidney disease; SBP — systolic blood pressure; DBP — diastolic blood pressure; GFR — glomerular filtration rate

comparable age and duration of $\mathrm{CKD}$ and $\mathrm{HTN}$, but proteinuric patients had more severe course of HTN, assessed by grade of HTN. Non-proteinuric patients achieved BP goals significantly more often, then those with proteinuria. Percentage of prescription antiproteinuric drugs such as angiotensin converting enzyme inhibitors (ACEI) and angiotensin receptor blockers (ARB) was $15.3 \%$ and $21.2 \%$.

Females achieved BP targets more often than males and in ACC 2017 group females' proportion was the highest (Tab. III). The lowest frequency of DM was in CCS 2018 group, the highest — in ACC 2017 group. We observed in all treated hypertensive patients, as compared to patients with controlled $\mathrm{BP}$, higher frequency of $\mathrm{LVH}$, proteinuria, higher median BMI, uric acid and lower median GFR. Prevalence of $\mathrm{LVH}$ and proteinuria was relatively low in ACC 2017 and KDIGO 2012 groups. Classes of antihypertensive drugs are ordered in frequency of usage. The most widely used classes were renin-an- 
Table III. Clinical characteristics of patients who achieved BP control according to different standards

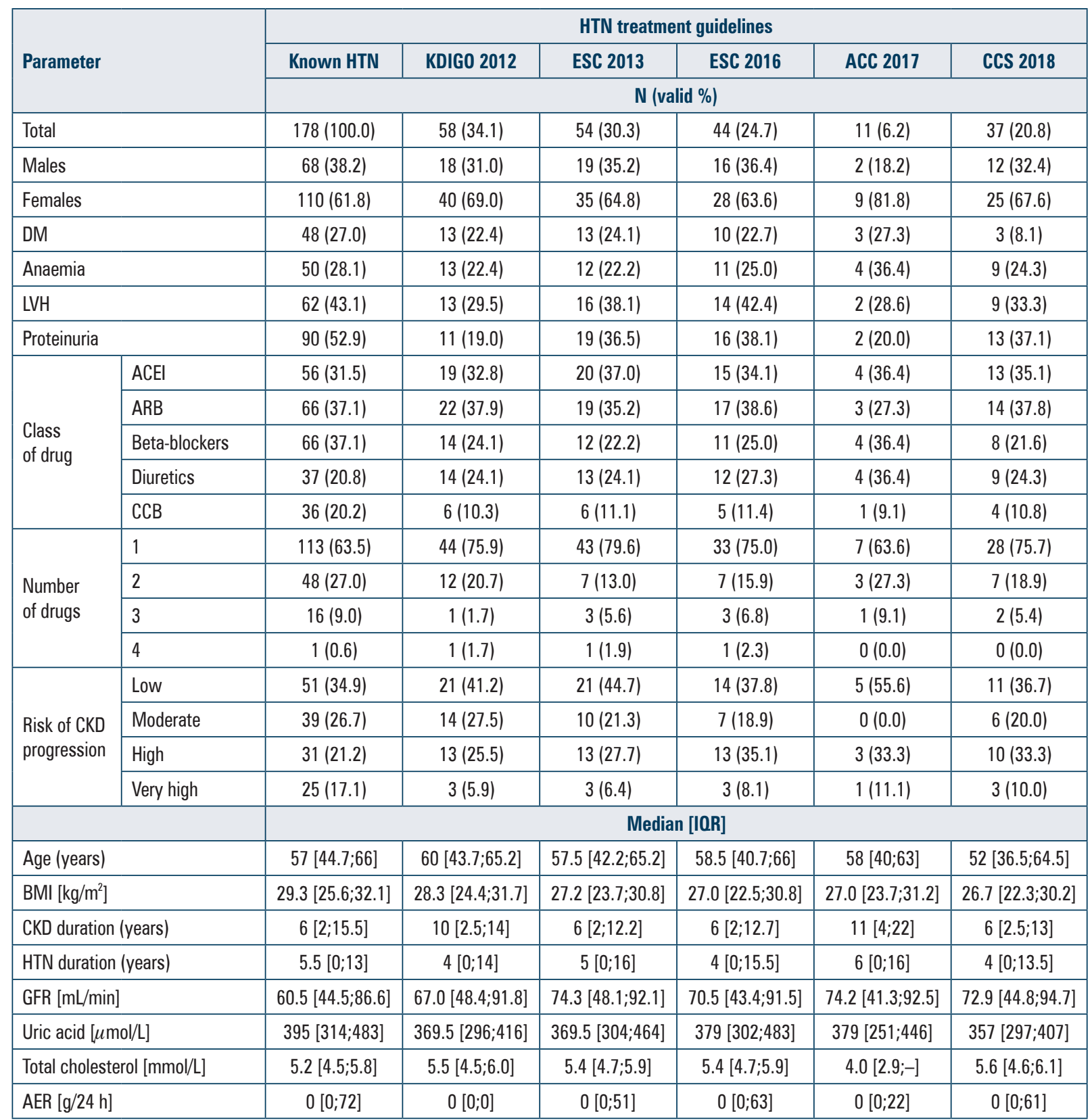

HTN — arterial hypertension; ESC — European Society of Cardiology; KDIGO — Kidney Disease Improving Global Outcomes; ACC — American College of Cardiology; CCS — Canadian Cardiovascular Society; DM — diabetes mellitus; LVH — left ventricle hypertrophy; ACEI — angiotensin converting enzyme inhibitors; ARB — angiotensin receptor blockers; CCB — calcium channel blockers; BMI — body mass index CKD — chronic kidney disease; SBP — systolic blood pressure; DBP — diastolic blood pressure; GFR — glomerular filtration rate; AER — albumin excretion rate

giotensin-aldosterone system blockers, and calcium channel blockers were used in the minority of cases. The most common mode of HTN treatment was monotherapy. In patients with controlled HTN, diuretics were used more commonly than in the whole cohort of patients receiving HTN treatment. The majority of patients with controlled HTN had low risk of $\mathrm{CKD}$ progression, regardless of chosen $\mathrm{BP}$ goals. Continuous values were roughly equal in all groups, but cholesterol level and GFR were slightly better in ACC 2017 group.

\section{Discussion}

Our study confirmed that HTN is highly prevalent among patients with CKD in ambulatory practice. The most optimal laboratory results and the lowest median age were observed in normotensive patients. This group also showed the highest proportion of low-risk patients for CKD progression. Slightly better clinical characteristics of patients with HTN de novo as compared to patients with known HTN may be explained by age differences (more than 15 years) and milder course of hypertension (assessed by BP 


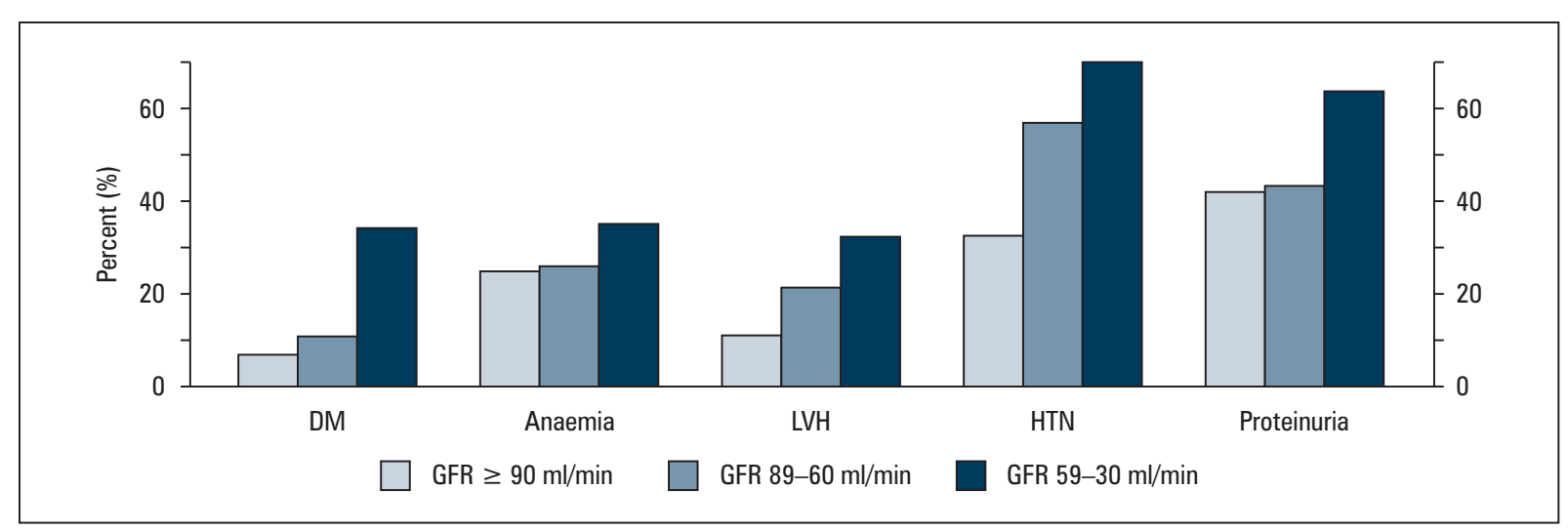

Figure 2. Prevalence of comorbidities depending on CKD stage. GFR — glomerular filtration rate; DM — diabetes mellitus; LVH — left ventricle hypertrophy; HTN — arterial hypertension

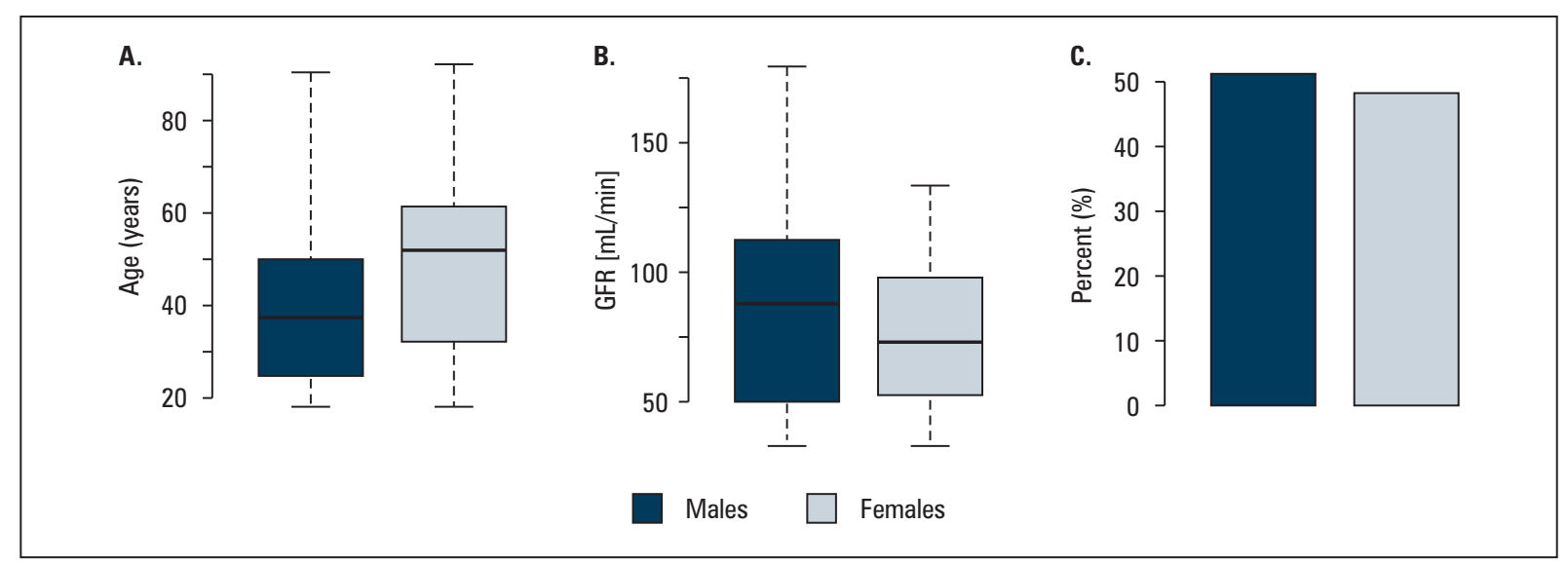

Figure 3. Age (A), glomerular filtration rate (GFR) (B) and prevalence of proteinuria (C) subdivided by gender in all patients in the study. Females were $\sim 15$ years older than males $(<0.001)$, but had comparable values of GFR and prevalence of proteinuria

levels and percentage of controlled BP). Nearly 50\% of patients had proteinuria, and this proportion was even higher in hypertensive patients, while it should not exceed 40\% according to Bolignano (2017) [4]. Forty-three percent of patients with known HTN had LVH, but even higher prevalence of LVH in hypertensive patients in Ukraine was given by Ragot [15]. This data indicate that HTN in Ukrainian patients, and in patients with CKD as well, is diagnosed with delay and BP control is not optimal. Hypertensive patients had higher risk of CKD progression and had significantly different GFR values, but not AER. We assume that in our cohort, the risk of CKD progression was in higher degree influenced by renal function loss.

Secondly, patients in our study differed from populations reported in other studies in several ways. Overall females' proportion in our study was slightly higher (Tab. I), while in meta-analysis of Mahmoodi et al. (2017) males were more prevalent in CKD populations [1]. At the same time, males predominated among patients with HTN de novo. Median age of males and females in our study was $37(24 ; 50)$ years and $52.5(33 ; 63)$ years, respectively (Fig. 3). The fact that males in our study were younger, than females may be explained by elevated alertness concerning evaluation of CV diseases in Ukrainian men. According to ESC: Cardiovascular Disease Statistics 2017 Ukrainian population (especially males) is at extremely high risk of mortality from $\mathrm{CV}$ disease complications [16]. Prevalence of DM among hypertensive patients was much higher, than in other groups (Tab. I), and than in official statistics [16, 17]. Prevalence of DM among general Ukrainian population is less than $3-4 \%[16,17]$, but nearly $18 \%$ in patients with hypertension [15]. According to the data from National Registry of patients with CKD (2016) prevalence of diabetic nephropathy among patients with CKD was 24\% for Ukraine and 23.2\% for Dnipropetrovsk region. But patients with type 2 
DM (which were included to our study) contributed only to $9.2 \%$ and $2.8 \%$ of patients for Ukraine and Dnipropetrovsk region respectively [18].

Next, we have found close interrelations between HTN, loss of renal function and proteinuria. Patients in our study showed deterioration of laboratory and instrumental findings and raise of comorbidity along with advance of CKD stage (Fig. 2) and these findings do not contradict existing concept of CKD progression [3]. In other study of Ukrainian patients with stage 4-5 CKD normal BP was observed only in $10 \%$ of patients, $\mathrm{LVH}$ - in $90 \%$ and more than half of patients had BMI more than $30 \mathrm{~kg} / \mathrm{m}^{2}$ [19]. Interestingly, decline of renal function is associated more strongly with CV risk factors than with AER. Severity of renal function loss is significantly associated with duration of HTN, but not duration of $\mathrm{CKD}$, and hypertensive patients seem to be that phenotype of CKD patients, prone to $\mathrm{CKD}$ progression. On average, proteinuric patients had preserved renal function (GFR $>60 \mathrm{ml} /$ $/ \mathrm{min}$ ) and more than $75 \%$ of proteinuric patients had HTN (Tab. II). Non-proteinuric patients had the same age, duration of CKD and HTN and gender composition, but they had $-15 \%$ significantly lower prevalence of HTN and significantly higher median GFR. Non-proteinuric patients had higher frequency of controlled BP. These data point out strong association of HTN, proteinuria and renal function loss and partially correspond with Bolignano's review [4]: we agree that $\mathrm{HTN}$ is responsible for GFR lowering, but we find no data that absence of proteinuria elevates risk of CKD progression. According to CKD-ROUTE study patients with normal-range proteinuria are not in higher risk of renal function loss as compared to non-proteinuric patients [20].

And, finally, there are several findings concerning antihypertensive treatment and achieving BP targets. Proportions of drug types in all treated patients and in patients who achieved BP targets were roughly equal (Tab. III). Beta-blockers were used slightly more often in controlled patients while these drugs are supposed to be used in specific comorbidities (heart failure, coronary artery disease, atrial fibrillation etc. $[8,21])$. CCB, that should be included into initial combination of antihypertensive drugs were used scarcely. The same pattern as in proportion of types of drugs was observed in number of used drugs. First of all, it may indicate on inadequate choice of dosage. The most common regimen was monotherapy $(60-80 \%)$, even higher in well-controlled patients (Tab. III), while guidelines state, that CKD patients usually require combination of antihypertensive drugs $[8-10,12,13,21]$. Overall effectiveness of monotherapy in our study did not exceed $25 \%$ and we suggest that wider usage of combined therapy will allow reaching BP targets in higher percent of patients. Important question is whether it should start from combination, or drugs should be added in stepwise manner, because it may influence frequency of drug-related side-effects as well as symptoms related to hypotension [22, 23].

Females achieved BP goals more often, regardless of chosen standard, which may be related to higher adherence to antihypertensive treatment [24]. Patients who achieved BP goals had the similar age, BMI, CKD and HTN duration, and DM prevalence as the whole cohort of hypertensive patients. Although overall proportion of controlled BP was low (34\% and less), it wasn't much lower, than in reported data [2]. Worth mentioning is the fact that approximately $70 \%$ of our patients received ACEI of $A R B$ and it is rather similar to reports form primary care practitioners in USA [2], but low percentage of renin-angiotensin-aldosterone blockers in patients with proteinuria (Tab. II) is troublesome. Notable, diuretics, that were used scarcely showed good effectiveness and their usage was more often in patients with controlled BP.

It is evident that achieving BP goals is beneficial, as patients with controlled HTN had better laboratory and instrumental findings (except of anaemia in ACC 2017 group). But it is still questionable whether achieving BP control allows improvement of patients' characteristics, and, thus, their estimated risks, or such a low intensity of antihypertensive treatment allows achieving BP goals only in relatively healthy subjects.

Patients who achieved BP levels of $<130 / 80 \mathrm{~mm} \mathrm{Hg}$ are prominent in following aspects:

- they had the most favourable laboratory parameters and low rates of LVH and proteinuria (albeit they had higher proportion of anaemia and DM);

- usage of beta-blockers and diuretics in this group of patients was the most common;

- antihypertensive therapy in this group was the most intensive;

- this group had the highest proportion of patients with low risk of CKD progression.

Non-beneficial, as compared with other groups age and duration of HTN and CKD allow us to suggest that these patients were in the same conditions with others. Kovesdy (2017) finds doubtful extrapolation of SPRINT trial results on general CKD population, mainly due to exclusion of patients with $\mathrm{DM}$ and heart failure from the trial [5]. Taking into 
account that $30 \%$ of patients in the group of strict control had DM, it is possible that achieving lower $\mathrm{BP}$ goals will result in better $\mathrm{CV}$ and $\mathrm{CKD}$ deterioration prognosis. But here we should also mention that usage of threshold of $130 / 80 \mathrm{mmHg}$ for diagnosis of HTN reclassified $34 \%$ of normotensive patients with CKD in our study as hypertensive ones. Labelling individual as having disease may per se lead to perception of poor health and elevating of BP values through different mechanisms [6].

\section{Conclusions}

Arterial hypertension occurs in $70 \%$ of patients with $\mathrm{CKD}$ and it is controlled in up to $34 \%$ cases. Usage of ACC 2017 blood pressure targets reclassifies 34\% of normotensive patients as hypertensive.

Arterial hypertension is important factor of CKD progression and it is closely connected with GFR and proteinuria. Treatment of proteinuria is crucial in achieving $\mathrm{BP}$ goals in patients with $\mathrm{CKD}$.

\section{Perspectives}

ESC/ESH 2018 guidelines for the management of $\mathrm{AH}$ (21) recommend $\mathrm{BB}$ to be used in young females or in patients with specific conditions (such as heart failure, atrial fibrillation, coronary artery disease etc.). Patients in our study poorly fit these criteria, but in $1 / 3$ of patients $\mathrm{BB}$ were used. Influence of $\mathrm{BB}$ on proteinuria and $\mathrm{CKD}$ progression is to be clarified.

According to our data patients with CKD stage 2 have similar risk of CKD progression but higher $\mathrm{CV}$ risks than patients with CKD stage 1 . Differences of $\mathrm{CV}$ and $\mathrm{CKD}$ progression risks in patients with CKD stages 1 and 2 are to be proven on larger patients cohorts.

\section{Limitations}

Patients in our study were referred to our centre by primary care practitioners because of new symptoms or deterioration and, thus, they do not correspond totally with patients with early CKD in ambulatory practice. The fact that $21 \%$ of patients in our study had HTN de novo confirms this idea.

Gender aspects of CKD progression. In our study males and females had age difference of $\sim 15$ years that determines difficulties in comparing these groups.

Effects of combinations of first-line antihypertensive drugs weren't investigated.

\section{Conflict of interests}

The authors report no conflicts of interest.

\section{References}

1. Mahmoodi BK, Matsushita K, Woodward M, et al. Chronic Kidney Disease Prognosis Consortium. Associations of kidney disease measures with mortality and end-stage renal disease in individuals with and without hypertension: a meta-analysis. Lancet. 2012; 380(9854): 1649-1661, doi: 10.1016/S0140-6736(12)61272-0, indexed in Pubmed: 23013600.

2. Wouters OJ, O’Donoghue DJ, Ritchie J, et al. Early chronic kidney disease: diagnosis, management and models of care. Nat Rev Nephrol. 2015; 11(8): 491-502, doi: $10.1038 /$ nrneph.2015.85, indexed in Pubmed: 26055354.

3. Judd E, Calhoun DA. Management of hypertension in CKD: beyond the guidelines. Adv Chronic Kidney Dis. 2015; 22(2): 116-122, doi: 10.1053/j.ackd.2014.12.001, indexed in Pubmed: 25704348.

4. Bolignano D, Zoccali C. Non-proteinuric rather than proteinuric renal diseases are the leading cause of end-stage kidney disease. Nephrol Dial Transplant. 2017; 32(suppl_2): ii194-ii199, doi: 10.1093/ ndt/gfw440, indexed in Pubmed: 28340010.

5. Kovesdy CP. Hypertension in chronic kidney disease after the Systolic Blood Pressure Intervention Trial: targets, treatment and current uncertainties. Nephrol Dial Transplant. 2017; 32(suppl_2): ii219_ ii223, doi: 10.1093/ndt/gfw269, indexed in Pubmed: 28201651.

6. Messerli FH, Rimoldi SF, Bangalore S. Changing definition of hypertension in guidelines: how innocent a number game? Eur Heart J. 2018;39(24): 2241-2242, doi: 10.1093/eurheartj/ehx806, indexed in Pubmed: 29324999.

7. Denic A, Glassock RJ, Rule AD. Structural and functional changes with the aging kidney. Adv Chronic Kidney Dis. 2016; 23(1): 19-28, doi: 10.1053/j.ackd.2015.08.004, indexed in Pubmed: 26709059.

8. Eknoyan G, Lameire N, Echardt K, et al. KDIGO Clinical Practice Guideline for the Management of Blood Pressure in Chronic Kidney Disease. Kidney Int. 2012; Supp 2(5)(1): 337-414.

9. Mancia G, Fagard R, Narkiewicz K. 2013 ESH/ESC guidelines for the management of arterial hypertension: the Task Force for the Management of Arterial Hypertension of the European Society of Hypertension (ESH) and of the European Society of Cardiology (ESC). Eur Heart J. 2013; 34(28): 2159-2219, doi: 10.1093/ eurheartj/eht151, indexed in Pubmed: 23771844.

10. Whelton P, Carey R, Aronow W, et al. 2017 ACC/AHA/AAPA/ABC/ ACPM/AGS/APhA/ASH/ASPC/NMA/PCNA Guideline for the Prevention, Detection, Evaluation, and Management of High Blood Pressure in Adults. J Am Coll Cardiol. 2018; 71(19): e127-e248, doi: 10.1016/j.jacc.2017.11.006, indexed in Pubmed: 29146535.

11. Beddhu S, Rocco MV, Toto R, et al. SPRINT Research Group. Effects of Intensive Systolic Blood Pressure Control on Kidney and Cardiovascular Outcomes in Persons Without Kidney Disease: A Secondary Analysis of a Randomized Trial. Ann Intern Med. 2017; 167(6): 375-383, doi: 10.7326/M16-2966, indexed in Pubmed: 28869987.

12. Nerenberg KA, Zarnke KB, Leung AA, et al. Hypertension Canada. Hypertension Canada's 2018 Guidelines for Diagnosis, Risk Assessment, Prevention, and Treatment of Hypertension in Adults and Children. Can J Cardiol. 2018; 34(5): 506-525, doi: 10.1016/j. cjca.2018.02.022, indexed in Pubmed: 29731013.

13. Piepoli MF, Hoes AW, Agewall S, et al. ESC Scientific Document Group. 2016 European Guidelines on cardiovascular disease prevention in clinical practice: The Sixth Joint Task Force of the European Society of Cardiology and Other Societies on Cardiovascular Disease Prevention in Clinical Practice (constituted by representatives of 10 societies and by invited experts) Developed with the special contribution of the European Association for Cardiovascular Prevention \& Rehabilitation (EACPR). Eur Heart J. 2016; 37(29): 2315-2381, doi: 10.1093/eurheartj/ehw106, indexed in Pubmed: 27222591.

14. Eknoyan G, Lameire N, Echardt K, et al. KDIGO 2012 Clinical Practice Guideline for the Evaluation and Management of Chronic Kidney Disease. Kidney Int Suppl [Internet]. 2013; 3(1): 1-150.

15. Ragot S, Beneteau M, Guillou-Bonnici F, et al. Prevalence and management of hypertensive patients in clinical practice: Cross-sectional 
registry in five countries outside the European Union. Blood Press. 2016; 25(2): 104-116, doi: 10.3109/08037051.2015.1110922, indexed in Pubmed: 26873621.

16. Timmis A, Townsend N, Gale C, et al. ESC Scientific Document Group . European Society of Cardiology: Cardiovascular Disease Statistics 2017. Eur Heart J. 2018; 39(7): 508-579, doi: 10.1093/ eurheartj/ehx628, indexed in Pubmed: 29190377.

17. Stel VS, Brück K, Fraser $S$, et al. International differences in chronic kidney disease prevalence: a key public health and epidemiologic research issue. Nephrol Dial Transplant. 2017; 32(suppl_2): ii129-ii135, doi: 10.1093/ndt/gfw420, indexed in Pubmed: 28206610.

18. Kozluk NI, Nykolaenko SS, Razvajaeva OO. State I "Institute of $\mathrm{NN}$ of U. National registry of patients with chronic kidney disease and acute kidney injury 2016: 201.

19. Kuryata OV, Frolova Y, Yashenko TD. Analysis of the factors of survival to renal replacement therapy in patients with chronic kidney disease. Kidneys. 2018; 7(3): 150-157, doi: 10.22141/23071257.7.3.2018.140198.

20. Iimori S, Naito $S$, Noda Y, et al. Prognosis of chronic kidney disease with normal-range proteinuria: The CKD-ROUTE study. PLoS
One. 2018; 13(1): e0190493, doi: 10.1371/journal.pone.0190493, indexed in Pubmed: 29342207.

21. Williams B, Mancia G, Spiering W, et al. Authors/Task Force Members:, ESC Scientific Document Group . 2018 ESC/ESH Guidelines for the management of arterial hypertension. Eur Heart J. 2018; 39(33): 3021-3104, doi: 10.1093/eurheartj/ehy339, indexed in Pubmed: 30165516.

22. Germany ECN 2018-M. 2018 ESC/ESH Clinical Practice Guidelines in the spotlight - Arterial Hypertension [Internet]. https:// www.escardio.org/Congresses-\&-Events/ESC-Congress/Congress-resources/Congress-news/2018-esc-esh-clinical-practiceguidelines-in-the-spotlight-arterial-hypertension (27 Aug 2018).

23. New blood pressure guidelines could put lives at risk [Internet]. https://sydney.edu.au/news-opinion/news/2018/04/17/bloodpressure---new-guidelines-could-put-lives-at-risk.html (17 April 2018).

24. Lefort M, Neufcourt L, Pannier B, et al. Sex differences in adherence to antihypertensive treatment in patients aged above 55: The French League Against Hypertension Survey (FLAHS). J Clin Hypertens (Greenwich). 2018; 20(10): 1496-1503, doi: 10.1111/jch.13387, indexed in Pubmed: 30238630. 